\title{
Intentional injury against children in Sub-Saharan Africa: A tertiary trauma centre experience
}

\author{
Jared R. Gallaher ${ }^{\mathrm{a}}$, Benjamin Wildfire ${ }^{\mathrm{b}}$, Charles Mabedi ${ }^{\mathrm{c}}$, Bruce A. Cairns ${ }^{\mathrm{d}}$, \\ Anthony G. Charles ${ }^{\mathrm{a}, \mathrm{c}, \mathrm{d}, *}$ \\ a Department of Surgery, University of North Carolina School of Medicine, Chapel Hill, NC CB\# 7228, USA \\ ${ }^{\mathrm{b}}$ UNICEF Malawi, PO Box 30375, Lilongwe 3, Malawi \\ ${ }^{\mathrm{c}}$ Department of Surgery, Kamuzu Central Hospital, Lilongwe, Malawi \\ ${ }^{\mathrm{d}}$ North Carolina Jaycee Burn Center, Department of Surgery, University of North Carolina School of Medicine, Chapel Hill, NC CB\# 7600, USA
}

A R T I C L E I N F O

Article history:

Accepted 27 October 2015

Keywords:

Intentional injury in children

Child abuse

Sub Saharan Africa

Malawi

Childhood injury

\begin{abstract}
A B S T R A C T
Background: Intentional injuries are the result of violence. This is an important public health issue, particularly in children, and is an unaddressed problem in sub-Saharan Africa. This study sought to describe the characteristics of intentional injury, particularly physical abuse, in children presenting to our tertiary trauma centre in Lilongwe, Malawi and how they compare to children with unintentional injuries.

Methods: A retrospective analysis of children ( $<18$ years old) with traumatic injuries presenting to Kamuzu Central Hospital (KCH) in Lilongwe, Malawi from 2009 to 2013 was performed. Children with intentional and unintentional injuries were compared with bivariate analysis and multivariate logistic regression modelling.

Results: 67,672 patients with traumatic injuries presented to $\mathrm{KCH}$ of which 24,365 were children. 1976 $(8.1 \%)$ patients presented with intentional injury. Intentional injury patients had a higher mean age ( $11.1 \pm 5.0$ vs. $7.1 \pm 4.6, p<0.001)$, a greater male preponderance ( 72.5 vs. $63.6 \%, p<0.001$ ), were more often injured at night $(38.3$ vs. $20.7 \%, p<0.001)$, and alcohol was more often involved $(7.8$ vs. $1.0 \%$, $p<0.001)$. Multivariate logistic regression modelling showed that increasing age, male gender, and nighttime or urban setting for injury were associated with increased odds of intentional injury. Soft tissue injuries were more common in intentional injury patients ( $80.5 \mathrm{vs.} 45.4 \%, p<0.001)$ and fist punches were the most common weapon (25.6\%). Most patients were discharged in both groups $(89.2 \mathrm{vs} 80.9 \%, p<0.001)$ and overall mortality was lower for intentional injury patients $(0.9$ vs. $1.2 \%, p=0.001)$. Head injury was the most common cause of death $(43.8$ vs. $32.2 \%, p<0.001)$ in both groups.

Conclusions: Sub-Saharan African tertiary hospitals are uniquely positioned to play a pivotal role in the identification, clinical management, and alleviation of intentional injuries to children by facilitating access to social services and through prevention efforts.
\end{abstract}

\section{Introduction}

The global burden of paediatric injury is well described, but under-reported as a public health crisis in sub-Saharan Africa [1-8]. Unfortunately, because communicable disease and nutritional problems still account for significantly higher causes of childhood mortality and morbidity in most of the developing

\footnotetext{
* Corresponding author at: School of Medicine University of North Carolina, 4008 Burnett Womack Building, Chapel Hill, NC CB 7228, USA. Tel.: +1 919966 4389; fax: +19199660369.

E-mail address: anthony_charles@med.unc.edu (A.G. Charles).
}

world, the relative importance of childhood injuries has historically been diminished. Injury mortality exceeds that of HIV, tuberculosis, and malaria combined in children five years of age and older [9] and this burden is disproportionately experienced in low- and middle-income countries (LMICs) where 95\% of paediatric deaths due to injury occur [10].

Intentional injury is the result of violence, which the World Health Organisation defines as, "the intentional use of physical force or power, threatened or actual, against oneself, another person, or against a group or community, that either results in or has a high likelihood of resulting in injury, death, psychological harm, maldevelopment or deprivation" [11]. As much as $7-10 \%$ of childhood injuries are intentional $[1,2,12]$, and some studies 
suggest that the incidence is even higher in low and middleincome countries $[13,14]$. This is important because intentional injuries are associated with many different health, family, and social consequences. For example, children in Malawi who undergo violence are more likely to experience mental distress, indulge in smoking or drug use, suffer sexually transmitted infection (STI), or engage in other self-harming behaviours [15]. Intentional injuries also resulted in the deaths of approximately 311,000 people in Africa in the year 2000, which is a rate of 60.9 deaths per 100,000 people. This figure far exceeds the intentional injury mortality rate in high-income countries of 14.4 deaths per 100,000 people and the unintentional injury mortality rates of both the WHO European and American regions at rates of 32.0 per 100,000 people [12]. Unfortunately, there is a dearth of data as to the true magnitude of childhood intentional injuries in subSaharan Africa.

Children in developing countries are one of the most vulnerable populations worldwide and healthcare providers have an obligation to advocate for their safety and health. Malawi, like many of the other countries in sub-Saharan Africa, is a poor country with approximately $45 \%$ of the population under the age of 14 years [16]. Given the size of this population and available data that demonstrates that violence against children is a significant issue, ascertaining the characteristics and associated epidemiology and outcomes of children utilizing available trauma services is imperative. Indeed, Malawi's Violence Against Children Survey suggests there is an under-utilisation of available services, with less than $10 \%$ of children suffering physical violence ever receiving any professional services [15]. These data will help inform policy decisions on improving trauma care and developing the associated social support services required. Therefore, we sought to describe the characteristics of paediatric intentional injury, how these injuries compare to unintentional injury, and the proportion of new trauma cases that were intentionally inflicted presenting to our tertiary trauma centre in Lilongwe, Malawi.

\section{Methods}

This study is a retrospective analysis of secondary data from the Kamuzu Central Hospital ( $\mathrm{KCH})$ Trauma Registry. $\mathrm{KCH}$ is a public 600-bed tertiary care hospital in the capital city of Lilongwe, which serves as a referral centre for approximately 5 million people in the central region of Malawi. $\mathrm{KCH}$ is equipped with four intensive care unit beds and four ventilators, a surgical step-down unit, and a paediatric ward. Trauma and orthopaedic surgical services are available seven days a week. Surgical consultants and Malawian general surgery registrars staff the trauma service.

The KCH Trauma Registry was established to collect patient demographic information, clinical characteristics, and outcome data of all patients presenting to the emergency department with traumatic injuries of any severity [17]. Specifically, data points utilised in this study for comparison include age, sex, date of injury, setting of injury, mechanism of injury, type and location of injury, the amount of time to presentation to the hospital, date of admission, clinical scoring systems such as the AVPU Scale, date and type of operative procedures, length of hospital stay, and outcome (discharge, abscond, or death). The AVPU scale records a patient's level of consciousness as either alert, responding to verbal stimuli, responding to pain stimuli, or unresponsive. It correlates with GCS and the United States ATLS protocol used it in the primary survey $[18,19]$.

All paediatric patients who presented to the emergency department with traumatic physical injuries over five years between January 2009 and December 2013 were included in this study. Patients 18 years old or older or patients missing a recorded age or birthdate were excluded from analysis. Intentional paediatric injury was classified as patients suffering a traumatic injury of any severity, including superficial injuries, with a mechanism coded as "assault" or with another mechanism but coded as "intentional." Nighttime was defined as the hours between 18:00 and 06:00. Overall crude mortality was calculated using any deaths declared in casualty or in the hospital against all paediatric patients recorded in the trauma registry. In-hospital mortality used the same methodology for recording deaths but excluded any patients discharged home from casualty.

We performed bivariate analysis using $\mathrm{Chi}^{2}$ tests, two-sample Student's t-tests, and one-way analysis of variance tests to compare variables between intentional and unintentional paediatric trauma patients. When comparing categorical variables with more than two categories, the aggregate of the remaining categories was used as the referent for comparison. The three most common mechanisms of assault were compared by median age using the Kruskal-Wallis test because age was not normally distributed. Bivariate analysis was performed to compare injury associations with mortality. Additionally, multivariate logistic regression modelling was used to examine the association between having an intentional injury and patient demographic factors and the characteristics of the injury setting. Tested variables were included based on clinical significance.

All statistical analysis was performed using Stata/SE 13.1 (Stata-Corp LP, College Station, TX). The University of North Carolina Institutional Review Board and the Malawi National Health Services Review Committee approved this study.

\section{Results}

67,672 patients with traumatic injuries presented to $\mathrm{KCH}$ during the study period that included 24,365 children (age $<18$ years). 760 patients (1.1\%) were missing a recorded age and were not included in the analysis. Mean age was $7.4(\mathrm{SD} \pm 4.8)$ years with a male preponderance of $64.4 \% .1976$ (8.1\%) paediatric patients suffered intentional injury in our study cohort.

There were significant differences in demographic and clinical characteristics between children with and without intentional injury. Children with intentional injury were more likely to be male, ( 72.5 vs. $63.6 \%, p<0.001)$ and were significantly older $(11.1$ $\mathrm{SD} \pm 5.0$ vs. $7.1 \mathrm{SD} \pm 4.6, p<0.001)$. Analysis of injury location comparing intentional to unintentional injuries revealed that though there are fewer intentional injuries occurring at home compared to unintentional injuries, approximately $60 \%$ of all intentional injuries occurred within the home (59.8 vs. $71.0 \%, p<0.001$ ). Furthermore, there was an increased preponderance of intentional injury occurring on the street ( 16.9 vs. $14.2 \%, p=0.001$ ), in public spaces ( 7.4 vs. $1.2 \%$, $p<0.001$ ), or at school ( 7.0 vs. $5.8 \%, p=0.022$ ). Similarly, intentional injuries occurred more often at night (38.3 vs. $20.7 \%, p<0.001)$ and alcohol was more often involved ( 7.8 vs. $1.0 \%, p<0.001$ ). Intentional injuries were also more likely to occur in an urban setting (44.4 vs. $40.6 \%, p=0.001$ ). The most common mode of transportation to the hospital was minibus for both groups ( 44.8 vs. $53.3 \%, p<0.001$ ) but police transport was more common for intentional injury (4.2 vs. $0.7 \%, p<0.001$ ) (Table 1 ).

There were no statistically significant differences in the initial presenting AVPU scores in the emergency department between the two trauma cohorts with over 95\% scoring "responds to voice" or "alert" ( $p=0.443)$. The admission rate to the hospital was much lower for intentional injury victims being admitted at almost half the rate ( 10.0 vs. $18.0 \%, p<0.001$ ) but the overwhelming majority in both groups were treated and discharged from the emergency department ( 89.2 vs. $80.9 \%, p<0.001$ ) (Table 1 ). Overall mortality for the victims of intentional and unintentional injuries was $0.9 \%$ $(18 / 1976)$ and $1.2 \%(263 / 22,389)$, respectively $(p=0.001)$. However, there were no statistically significant differences in-hospital 
Table 1

Bivariate analysis of demographic and clinical characteristics of paediatric patients presenting with traumatic injuries by intentionality.

\begin{tabular}{|c|c|c|c|}
\hline & $\begin{array}{l}\text { Intentional } \\
\text { injury } \\
\text { patients } \\
(n=1976)\end{array}$ & $\begin{array}{l}\text { Unintentional } \\
\text { injury patients } \\
(n=22,389)\end{array}$ & $p$ Value \\
\hline \multicolumn{4}{|l|}{ Patient age (years) } \\
\hline Mean \pm SD & $11.1 \pm 5.0$ & $7.1 \pm 4.6$ & $<0.001$ \\
\hline \multicolumn{4}{|l|}{ Sex: $N(\%)$} \\
\hline Female & $540(27.4)$ & $8125(36.3)$ & $<0.001$ \\
\hline Male & $1433(72.5)$ & $14,232(63.6)$ & \\
\hline Missing & $3(0.1)$ & $32(0.1)$ & \\
\hline \multicolumn{4}{|l|}{ Setting of injury: $N(\%)$} \\
\hline Home & $1182(59.8)$ & $15,904(71.0)$ & $<0.001$ \\
\hline School & $139(7.0)$ & $1296(5.8)$ & 0.022 \\
\hline Street & $334(16.9)$ & $3179(14.2)$ & 0.001 \\
\hline Public space & $147(7.4)$ & $262(1.2)$ & $<0.001$ \\
\hline Work & $26(1.3)$ & $155(0.7)$ & 0.002 \\
\hline Other & $78(4.0)$ & $851(3.8)$ & 0.729 \\
\hline Missing & $78(3.6)$ & $742(3.3)$ & 0.588 \\
\hline \multicolumn{4}{|l|}{$\begin{array}{l}\text { Injury occurred at night: } \\
\quad N(\%)\end{array}$} \\
\hline Nighttime & $757(38.3)$ & $4633(20.7)$ & $<0.001$ \\
\hline Missing & $11(0.6)$ & $199(0.9)$ & \\
\hline \multicolumn{4}{|l|}{$\begin{array}{l}\text { Injury occurred in urban } \\
\text { vs. rural: } N(\%)\end{array}$} \\
\hline Urban & $878(44.4)$ & $9096(40.6)$ & \\
\hline Rural & $1087(55.0)$ & $13,072(58.4)$ & 0.001 \\
\hline Missing & $11(0.6)$ & $221(1.0)$ & \\
\hline \multicolumn{4}{|l|}{$\begin{array}{l}\text { Was alcohol involved: } \\
\quad N(\%)\end{array}$} \\
\hline Yes & $153(7.8)$ & $225(1.0)$ & \\
\hline No & $1816(91.9)$ & $21,967(98.0)$ & $<0.001$ \\
\hline Missing & $7(0.3)$ & $197(0.9)$ & \\
\hline \multicolumn{4}{|l|}{$\begin{array}{l}\text { Hours to presentation } \\
\text { from injury }\end{array}$} \\
\hline Mean \pm SD & $16.6 \pm 51.5$ & $24.1 \pm 121.2$ & 0.007 \\
\hline Missing (\%) & $48(2.4)$ & $508(2.3)$ & \\
\hline \multicolumn{4}{|l|}{ Transport to hospital } \\
\hline Minibus & $885(44.8)$ & $11,941(53.3)$ & $<0.001$ \\
\hline Private vehicle & $704(35.6)$ & $5504(24.6)$ & $<0.001$ \\
\hline Ambulance & $123(6.2)$ & $2970(13.3)$ & $<0.001$ \\
\hline Walked & $147(7.4)$ & $1255(5.6)$ & 0.001 \\
\hline Police & $82(4.2)$ & $152(0.7)$ & $<0.001$ \\
\hline Other & $27(1.4)$ & $368(1.6)$ & 0.337 \\
\hline Missing & $8(0.4)$ & $199(0.9)$ & 0.025 \\
\hline \multicolumn{4}{|l|}{ Initial AVPU score: $N(\%)$} \\
\hline Unresponsive & $11(0.6)$ & $119(0.5)$ & \\
\hline Responds to pain & $0(0.0)$ & $40(0.2)$ & 0.443 \\
\hline Responds to voice & $846(42.8)$ & $9572(42.8)$ & \\
\hline Alert & $1085(54.9)$ & $12,301(54.9)$ & \\
\hline Missing & $34(1.7)$ & $357(1.6)$ & \\
\hline \multicolumn{4}{|l|}{$\begin{array}{l}\text { Disposition from casualty: } \\
\quad N(\%)\end{array}$} \\
\hline Treated and discharged & $1763(89.2)$ & $18,101(80.9)$ & \\
\hline Admitted to hospital & $196(10.0)$ & $4014(18.0)$ & $<0.001$ \\
\hline Death declared in casualty & $14(0.7)$ & $148(0.7)$ & \\
\hline Missing & $3(0.1)$ & $126(0.6)$ & \\
\hline \multicolumn{4}{|l|}{ Mortality: $N(\%)$} \\
\hline Overall mortality & $18(0.9)$ & $263(1.2)$ & 0.001 \\
\hline In-hospital mortality & $18(8.5)$ & $263(6.1)$ & 0.162 \\
\hline Missing & $61(3.1)$ & $1082(4.8)$ & \\
\hline
\end{tabular}

mortality rates between the two groups ( 8.5 vs. $6.1 \%, p=0.162$ ). The most common injury associated with death among intentional injury victims was traumatic brain injury, which occurred in $43.8 \%$ of patients compared to $32.2 \%$ in the unintentional injury cohort $(p<0.001)$.

Multivariate logistic regression modelling showed several factors with significant associations with intentional injury in comparison to unintentional injury. Increasing age and male gender had significant associations with an odds ratio of 1.19 (95\% $\mathrm{CI}, 1.17,1.20)$ and $1.39(95 \% \mathrm{CI}, 1.24,1.55)$, respectively. An injury occurring in an urban setting versus a rural setting was also significantly associated with intentional injury with an odds ratio of 1.19 ( $95 \% \mathrm{CI}, 1.07,1.31)$ but a nighttime injury had the strongest association with an odds ratio of 2.27 (95\% CI, 2.05, 2.52). Neither an injury occurring at home compared to other settings nor hours to presentation from injury had a significant relationship to injury intentionality (Table 2).

In the intentional injury cohort, in $96 \%$ of victims the mechanism of injury was physical altercation or assault followed by human bite at $1.7 \%$. Assault victims were primarily attacked with a knife or other sharp object (28.7\%), stone or brick (23.7\%), or fists $(21.4 \%)$. Other metal objects were also common (9.2\%) as well as sticks (5.6\%) and tools (4.5\%). The use of firearm injuries was $1.1 \%$. There were significant differences in the three most common weapons based on the age of the victim. The median age for knives or sharp objects was 14 years (IQR 7-16) while it was 8 years (IQR $5-13)$ for stones, and 12 years (IQR $7-15)$ for fists $(p=0.0001)$. Stones were more common for children aged 3-10 years with fists being more common in very young children ( $0-2$ years). Knives and sharp objects were the dominant weapon in adolescents beginning at age 14 accounting for almost half of assaults by the age of 17.

Primary injuries from intentional trauma were overwhelmingly soft tissue (80.5\%), followed by fracture (5.5\%) and penetrating wounds (5.4\%). This pattern was in sharp contrast to patients with unintentional injuries, where soft tissue injuries only comprised $45.4 \%$ of all injuries with fracture being the second most common at $23.7 \%(p<0.001)$ (Table 3$)$. The pattern of primary injury location also differed. Almost half of the intentional injury victims, $48.8 \%$, had injuries to their head and face, compared to just $19.3 \%$ of other trauma patients $(p<0.001)$. Unintentional trauma patients had proportionally more injuries to the upper (9.9 vs. $28.2 \%$, $p<0.001)$ and lower extremities (12.2 vs. $24.8 \%, p<0.001)$. Injuries to the chest ( $5.4 \mathrm{vs} .2 .7 \%, p<0.001$ ) and abdomen ( $4.5 \mathrm{vs}$. $4.3 \%, p=0.825$ ) were not common in either group (Table 3 ).

Subset analysis of admitted paediatric trauma patients revealed fewer in-hospital days in victims of intentional injury compared to the unintentional injury cohort with a mean length of stay of 10.8 ( $\mathrm{SD} \pm 13.6$ days) and $13.6 \mathrm{SD}( \pm 15.9$ days), respectively $(p=0.0436)$. The rate of required surgical intervention was similarly low in both groups ( 14.6 vs. $14.9 \%, p=0.897$ ). The most common procedure for both groups was wound debridement/repair but the rate was nearly double in the intentional injury group ( 48.4 vs. $25.4 \%, p=0.005$ ). Interestingly, exploratory laparotomy was more common in the intentional injury cohort but still a relatively small percentage of all procedures ( 12.9 vs. $5.6 \%, p=0.096$ ). Orthopaedic surgical procedures were similar in the two cohorts ( 16.1 vs. $24.6 \%, p=0.282$ ).

Table 2

Multivariate logistic regression model analysing the association between intentional traumatic injury and patient demographics and the characteristics of the injury setting.

\begin{tabular}{lllr}
\hline & $\begin{array}{l}\text { Odds ratio of } \\
\text { intentional } \\
\text { injury }\end{array}$ & $\begin{array}{l}\text { 95\% } \\
\text { Confidence } \\
\text { interval }\end{array}$ & $p$ Value \\
\hline $\begin{array}{l}\text { Demographics and setting } \\
\text { characteristics }\end{array}$ & & & \\
Age & 1.19 & $1.17,1.20$ & $<0.001$ \\
Male gender & 1.39 & $1.24,1.55$ & $<0.001$ \\
Injury occurred at home & 1.05 & $0.94,1.17$ & 0.397 \\
$\quad$ Hours to presentation & 1.00 & $1.00,1.00$ & 0.002 \\
$\quad$ Injury occurred in urban area & 1.19 & $1.07,1.31$ & 0.001 \\
$\quad$ Injury occurred at night & 2.27 & $2.05,2.52$ & $<0.001$ \\
\hline
\end{tabular}


Table 3

Bivariate analysis of most severe traumatic injury type and location of paediatric trauma patients by intentionality.

\begin{tabular}{|c|c|c|c|}
\hline & $\begin{array}{l}\text { Intentional } \\
\text { injury } \\
\text { patients } \\
(n=1976)\end{array}$ & $\begin{array}{l}\text { Unintentional } \\
\text { injury patients } \\
(n=22,389)\end{array}$ & $p$ Value \\
\hline \multicolumn{4}{|l|}{$\begin{array}{l}\text { Most severe injury type: } \\
N(\%)\end{array}$} \\
\hline Soft tissue injury & $1591(80.5)$ & $10,166(45.4)$ & $<0.001$ \\
\hline Fracture & $108(5.5)$ & $5320(23.7)$ & $<0.001$ \\
\hline Dislocation & $25(1.3)$ & $916(4.1)$ & $<0.001$ \\
\hline Traumatic brain injury & $44(2.2)$ & $485(2.2)$ & 0.852 \\
\hline Penetrating wound & $106(5.4)$ & $69(0.3)$ & $<0.001$ \\
\hline Bite & $30(1.5)$ & $953(4.3)$ & $<0.001$ \\
\hline Burn & $15(0.7)$ & 2377 (10.6) & $<0.001$ \\
\hline Other & $41(2.1)$ & $1954(8.7)$ & $<0.001$ \\
\hline Missing & $16(0.8)$ & $149(0.7)$ & 0.454 \\
\hline \multicolumn{4}{|l|}{$\begin{array}{l}\text { Location of most severe } \\
\text { injury: } N(\%)\end{array}$} \\
\hline Head of face & $965(48.8)$ & 4,329 (19.3) & $<0.001$ \\
\hline Spine & $97(4.9)$ & $860(3.8)$ & 0.039 \\
\hline Chest & $106(5.4)$ & $593(2.7)$ & $<0.001$ \\
\hline Upper extremity & 195 (9.9) & $6316(28.2)$ & 0.852 \\
\hline Hand & $231(11.7)$ & $2810(12.6)$ & $<0.001$ \\
\hline Abdomen/flank & $88(4.4)$ & $970(4.3)$ & 0.551 \\
\hline Pelvis & $20(1.0)$ & $525(2.3)$ & $<0.001$ \\
\hline Lower extremity & $242(12.3)$ & $5546(24.8)$ & $<0.001$ \\
\hline Missing & $32(1.6)$ & $440(2.0)$ & 0.285 \\
\hline
\end{tabular}

\section{Discussion}

Intentional injury to children is a major public health and human rights issue that has remained a neglected problem despite its burden and impact on children, families, and society. Our study demonstrates that an intentional injury in children is common at our centre, comprising $8.1 \%$ of new paediatric trauma cases over the five years of the study period. Child victims of intentional injury present with varying demographic and injury patterns in comparison with paediatric trauma patients who suffer unintentional injury. Notably, increasing age, male gender, and an urban or nighttime injury setting were associated with intentionality. However, clinical outcomes are similar between the intentional and unintentional cohorts.

Evidence shows that in developing countries with available data, over three-fourths of children report suffering from physical punishment at home with almost $20 \%$ of children experiencing severe violence [20]. As reported by the WHO, in Egypt $37 \%$ of all children face severe physical punishment from their parents, comparable with observations from the Republic of Korea (45\%), Romania (50\%) Ethiopia (64\%), India (36\%), and the Philippines (21\%) [11]. Besides physical abuse, children are also often victims of emotional and psychological abuse at home, and annually 133 to 275 million children witness domestic violence in their families [21].

In Malawi, violence against children is widespread with over half of all children reporting at least one episode of physical violence before the age of 18 [15]. Normative cultural behaviour, including the use of corporal punishment, creates a maladaptive, acceptable environment conducive to escalating micro-violence within the community, which likely contributes to the increased incidence of intentional injuries. Furthermore, when instances of overt physical, sexual, or other violence against children are acknowledged, it is unaddressed and considered to be a private family matter. Governments in the region recognise abuse, exploitation, and violence against children as an area for concern. While provisions addressing violence against children exist in national legal and policy frameworks [7,22], there is often a lack of harmonisation with international child rights standards and implementation of these laws is poor.

Consequently, clinicians have a crucial role to play in the identification and management of intentional injuries at the point of contact with patient-victims. This includes promoting coordination with other crucial service providers such as social welfare and police. As information about child abuse or mistreatment is seldom volunteered, it usually goes unreported. Strategies to help alleviate this problem may include a mandatory reporting law, which has not been promulgated in many countries in this region. A study from Cameroon demonstrated a significant increase in provider identification of paediatric victims after a prevention and awareness programme aimed at emergency physicians [23]. These types of programmes would likely prove effective at improving identification and subsequent referral to law enforcement or social welfare services in other sub-Saharan Africa trauma centres. Another common approach to addressing violence in low-resource settings has been the development of One Stop Centres. These are often situated in hospitals and provide comprehensive service delivery, allowing victims of violence to access medical, psychosocial, police, and legal services all in one location [24]. Outreach to local communities and school-based girls and boys empowerment programmes will also help raise awareness and understanding, thereby empowering communities at the grass root level to take the lead in addressing violence, particularly against children. This type of outreach could also improve service utilisation, which is extremely low in Malawi at less than 10\% [15].

Our study is limited by its retrospective methodology. This is a limited sampling of patients with intentional injury significant enough to seek medical care at our tertiary centre in Lilongwe and report an intentional mechanism of injury. This exposes our sample to selection, presentation, and reporting bias. Furthermore, this is a hospital-based study which, given the limited access to hospital care and emergency transport in sub-Saharan Africa, our study sample is unlikely to be truly representative. However, hospital records and hospital-based studies make it possible to draw some generalisations about the relative weight of various causes of injury, especially for those injuries serious enough to receive formal care in large medical centres. Lastly, our study does not address sexual violence with no reported incidents. Given the results of the Malawian national survey [15] and other studies in sub-Saharan Africa [25,26], this is clearly a significant issue and is likely under-reported in our data.

\section{Conclusion}

The demographic characteristics and injury patterns of children suffering intentional injury differ from those with unintentional injuries. Consequently, sub-Saharan African tertiary hospitals are uniquely positioned to play a pivotal role in the identification, clinical management, and alleviation of intentional injuries to children by facilitating access to social services and ultimately through prevention efforts. However, more studies are warranted from sub-Saharan Africa to accurately assess the burden, consequences, and solutions to intentional injuries in children.

\section{Author contributions}

1. Jared R. Gallaher, MD contributed to this paper by: design of study, acquisition, analysis, and interpretation of data, drafting and revision of the manuscript, and statistical analysis.

2. Benjamin Wildfire, JD contributed to this paper by: design of study, interpretation of data, and drafting and revision of the manuscript. 
3. Charles Mabedi, MBBS contributed to this paper by: design of study, critical revision of the manuscript for important intellectual content, and administrative and technical support.

4. Bruce A. Cairns, MD contributed to this paper by: conception of the study, critical revision of the manuscript for important intellectual content, supervision, and the obtaining of funding.

5. Anthony G. Charles, MD, MPH contributed to this paper by: conception and design of the study, acquisition, analysis, and interpretation of data, drafting and revision of the manuscript, statistical analysis, obtaining of funding, and supervision.

\section{Access to data}

Jared R. Gallaher, MD and Anthony G. Charles, MD, MPH had full access to all of the data in the study and takes responsibility for the integrity of the data and the accuracy of the data analysis.

\section{Financial support}

Financial support was provided by the Department of Surgery at the University of North Carolina for all aspects of the study including: design and conduct of the study; collection, management, analysis, and interpretation of the data; and preparation, review, or approval of the manuscript.

\section{Conflict of interest statement}

The authors have no conflict of interest to disclose. The authors have no financial relationships to disclose.

\section{Data presented}

None.

\section{Acknowledgements}

None.

\section{References}

[1] Herbert HK, van As AB, Bachani AM, et al. Patterns of pediatric injury in South Africa: an analysis of hospital data between 1997 and 2006. J Trauma Acute Care Surg 2012;73(1):168-74

[2] Kiser MM, Samuel JC, Mclean SE, et al. Epidemiology of pediatric injury in Malawi: burden of disease and implications for prevention. Int J Surg 2012;10(10):611-7.

[3] de Sousa Petersburgo D, Keyes CE, Wright DW, et al. The epidemiology of childhood injury in Maputo, Mozambique. Int J Emerg Med 2010;3(3):157-63.

[4] Meel BL. Mortality of children in the Transkei region of South Africa. Am J Forensic Med Pathol 2003;24(2):141-7.

[5] Shen C, Sanno-Duanda B, Bickler SW. Pediatric trauma at a government referral hospital in The Gambia. West Afr J Med 2003;22(4):287-90.
[6] Ozgediz D, Riviello R. The "other" neglected diseases in global public health: surgical conditions in sub-Saharan Africa. PLoS Med 2008:5(6):e121.

[7] Abdur-Rahman LO, van As ABS, Rode H. Pediatric trauma care in Africa: the evolution and challenges. Semin Pediatr Surg 2012;21(2):111-5.

[8] Mutto M, Lawoko S, Nansamba C, et al. Unintentional childhood injury patterns, odds, and outcomes in Kampala City: an analysis of surveillance data from the National Pediatric Emergency Unit. J Inj Violence Res 2011;3(1): $13-8$.

[9] Lopez AD, Mathers CD, Ezzati M, et al. Measuring the global burden of disease and risk factors, 1990-2001. World Bank: Washington, DC; 2006.

[10] World Health Organization. Child and adolescent injury prevention: a WHO plan of action 2006-2015. World Health Organization; 2006, Available at: (http://whqlibdoc.who.int/publications/2006/9241593385_eng.pdf (accessed 3 June 2015)

[11] Krug EG, Dahlberg LL, Mercy JA, et al. World report on violence and health. World Health Organization; 2002, Available at: /http://whqlibdoc.who.int/ publications/2002/9241545615_eng.pdf (accessed 3 June 2015).

[12] Sebastian van As AB. Paediatric trauma care. Afr J Paediatr Surg 2010;7(3): 129-33.

[13] Hsia Renee, Ozgediz Doruk, Jayaraman Sudha, et al. Epidemiology of child injuries in Uganda: challenges for health policy. J Public Health Afr 2011;2(1):e15. http://dx.doi.org/10.4081/jphia.2011.e15.

[14] Hughes K, Bellis MA, Hardcastke KA, et al. Global development and diffusion of outcome evaluation research for interpersonal and self-directed violence prevention from 2007 to 2013: a systematic review. Aggress Violent Behav 2014;19(6):652-5.

[15] Ministry of Gender, Children, Disability and Social Welfare of the Republic of Malawi, United Nations Children's Fund. et al. Violence against children and young women in Malawi: findings from a National Survey, 2013. Government of Malawi; 2014, Available at: 〈http://www.unicef.org/malawi/MLW_ resources_violencereport.pdf) (accessed 3 June 2015).

[16] World Bank. World development indicators online. Data|The World Bank; 2014, Available at: 〈http://data.worldbank.org/indicator/SP.POP.0014.TO.ZS〉 (accessed June 21, 2015)

[17] Samuel JC, Akinkuotu A, Villaveces A, et al. Epidemiology of injuries at a tertiary care center in Malawi. World J Surg 2009;33(9):1836-41.

[18] Kelly CA, Upex A, Bateman DN. Comparison of consciousness level assessment in the poisoned patient using the alert/verbal/painful/unresponsive scale and the Glasgow Coma Scale. Ann Emerg Med 2004;44(2):108-13. http:// dx.doi.org/10.1016/S0196064404003105.

[19] American College of Surgeons Committee on Trauma. Advanced trauma life support for doctors: instructor course manual. 6th ed. Chicago, IL: American College of Surgeons; 1997.

[20] UNICEF. Child protection from violence, exploitation and abuse. UNICEF; 2011, Available at: 〈http://www.childinfo.org/files/ChildProtection_from_ violence_exploitation_abuse.pdf $\rangle$ (accessed 3 June 2015).

[21] (a) United Nations. Report of the independent expert for the United Nations study on violence against children. United Nations General Assembly; 2006, Available at: 〈http://www.unicef.org/violencestudy/reports/SG_ violencestudy_en.pdf (accessed 3 June 2015);

(b) Lachman P. Child protection in Africa-the road ahead. Child Abuse Negl 1996;20(7):543-7.

[22] Menick DM, Ngoh F. Child abuse in Cameroon: evaluation of a training course on awareness, detection, and reporting of child abuse. Med Trop 2005;65(1): $33-8$.

[23] Ellsberg M, Arango DJ, Morton M, et al. Prevention of violence against women and girls: what does the evidence say? Lancet 2015;385(9977):1555-66

[24] Badejoko OO, Anyabolu HC, Badejoko BO. Sexual assault in Ile-Ife, Nigeria. Niger Med J 2014;55(3):254-9.

[25] Melesse F, Kassie A. Child abuse in urban setting: a one-year analysis of hospital information on abused children at Yekatit 12 hospital, Addis Ababa. Ethiop Med J 2005;43(4):223-32.

[26] Cox S, Andrade G, Lungelow D. The child rape epidemic: assessing the incidence at Red Cross Hospital, Cape Town, and establishing the need for a new national protocol. S Afr Med J. 2007;97(10):950-5. 